\title{
Torilis japonica extract, a new potential EMT suppressor agent by regulation of EGFR signaling pathways
}

\author{
GUEN TAE KIM, SE HEE LEE and YOUNG MIN KIM \\ Department of Biological Sciences, College of Life Science and Nano Technology, \\ Hannam University, Yuseong-gu, Daejeon 305-811, Republic of Korea
}

Received May 3, 2014; Accepted July 2, 2014

DOI: $10.3892 /$ ijo.2014.2546

\begin{abstract}
Abnormal metastasis of carcinoma is associated with the loss of epithelial features and the acquisition of a mesenchymal phenotype. The stimulation of cells with epidermal growth factor (EGF) resulted in morphological changes and induced epithelial-mesenchymal transition (EMT). EGF stimulation resulted in increased mobility along with upregulated actin polarization related proteins, E-cadherin regulators and the mesenchymal markers. Treatment with Torilis japonica extract (TJE) along with stimulation by EGF prevented changes in cell morphology, mobility, expression of actin polarization proteins and EMT markers. Using specific inhibitors and siEGFR, it was demonstrated that TJE suppressed EMT through EGFR inactivation and regulation of its downstream signaling pathways. We suggest that TJE is a new potential reagent for EGFR-targeted therapy and antiabnormal metastasis in MCF-7 breast cancer.
\end{abstract}

\section{Introduction}

Epithelial-mesenchymal transition (EMT) is a biological process that allows a polarized epithelial cell to undergo biological changes that enable it assume a mesenchymal cell phenotype, for example, invasion, migration, and increased production of metastasis related components. A general character of EMT is degradation of the underlying basement membrane and the formation of a mesenchymal cell that can migrate from its origin, which is the epithelial layer. EMT is associated with implantation, embryo formation, and organ development, and it has the ability for wound healing and tissue regeneration (1-4); however, in case cells have undergone genetic and epigenetic changes such as an overexpressed

Correspondence to: Professor Young Min Kim, Department of Biological Sciences, College of Life Science and Nano Technology, Hannam University, Yuseong-dero 1646, Yuseong-gu, Daejeon 305-811, Republic of Korea

E-mail:kym@hnu.kr

Key words: Torilis japonica extract, EGFR, anti-metastasis, breast cancer oncogene or over-activation of growth factor receptors, EMT occurs excessively and these effects lead to abnormal metastasis (5-7).

A representative example of this phenomenon is abnormal metastasis of cancer cells. Induction of EMT by cancer cells is driven through the complex interplay between the tumor environment and cells (8). Some growth factors can promote EMT by triggering of specific intracellular signaling pathways, and this is closely associated with EGF, VEGF and TGF $(9,10)$. Especially, activation of epidermal growth factor receptor (EGFR) by EGF may play significant roles in cancer EMT (11-13). A main point of these signaling events is the loosening of the E-cadherin mediated cell to cell interaction that results from the expression of several transcriptional repressors such as Snail, Slug, Twist, and Zinc finger E-box binding homeobox (ZEB) (14-17). It has been reported previously that cells show an increase in mesenchymal markers such as vimentin and $\mathrm{N}$-cadherin in case of a change in phenotype during the EMT process $(18,19)$. Furthermore, cancer cells committed to EMT exhibit increased mobility by the activation of cell polarization related proteins such as VEGF and p-VASP (10,20-23). Blocking this process would be a therapeutic strategy to limit abnormal metastasis of cancer cells.

A number of studies have investigated the beneficial effects of diet on cancer prevention. In particular, the finding in recent studies that cancers that were often seen in Western countries, such as breast cancer or stomach cancer, are now frequently diagnosed in eastern countries is thought to reflect a change in dietary patterns $(24,25)$. For this reason, there has been an increase in using food ingredients for the prevention and treatment of cancer. In particular, attention has been paid to herbs that are used in eastern medicine. Recently research has found that herb medicines are effective in inhibiting cancer proliferation and invasion and have fewer side-effects than existing drugs $(26,27)$.

In this study, we investigated a specific herb for anti-metastasis in MCF-7 breast cancer cells. The fruit of Torilis japonica is used as a substitute for 'She chuang zi', which is a principal Chinese medicament prescribed as an anti-allergenic, antifungal, antibacterial and sedative agent. In addition, several books state that this herb is effective against tumors; however, these effects have not been examined scientifically $(28,29)$. Consequently, we investigated an ethanol extract from the fruit of Torilis japonica (TJE) and showed that it suppresses EGFR 
phosphorylation and its downstream proteins. In addition, despite EGF-stimulation, TJE treated groups showed induced E-cadherin expression levels and reduced metastasis-related proteins such as VEGF and p-VASP. Also TJE repressed expression of EMT markers. Taken together, the results show that TJE suppresses cell polarity and loss of cell-cell contact for the inhibition of abnormal metastasis.

Our results indicate that TJE is a new potential food ingredient for EGFR-targeted therapy for anti-abnormal metastasis in MCF-7 breast cancer cells.

\section{Materials and methods}

Plant material and preparation of TJE. Dried whole fruit of Torilis japonica was purchased from Na-num Pharmacy (Na-num Pharmacy, Kyung-buk, Korea). Plant material $(200 \mathrm{~g})$ was extracted two times with $95 \%$ ethanol at room temperature for 3 days and was subsequently filtered. The combined filtrate was concentrated under vacuum at $60^{\circ} \mathrm{C}$, and completely dried by freeze drying. The yield was $10 \%$ and TJE powder was dissolved in DMSO for in vitro studies.

Reagent. MTT and Phalloidin, EGF, PD 98059, LY 294002 are purchased from Sigma-Aldrich (Sigma-Aldrich, St. Louis, MO, USA). Avastin are purchased from Roche (Roche Applied Science, Basel, Switzerland). Specific antibodies that recognized p-EGFR, p-Akt, p-Erk, Akt, Erk, $\beta$-actin are obtained from Cell Signaling Technology (Beverly, MA, USA) and EGFR, VEGF, VASP and p-VASP are purchased from Santa Cruz Biotechnology (Dallas, TX, USA).

Cell culture. MCF-7 cells were obtained from the American Type Culture Collection (ATCC, Rockville, MD, USA). Cells were grown in RPMI-1640 medium for MCF-7 (Hyclone, Waltham, MA, USA) containing $10 \%$ fetal bovine serum (Hyclone) and $1 \%$ antibiotics $(100 \mathrm{mg} / 1$ streptomycin, $100 \mathrm{U} / \mathrm{ml}$ penicillin) at $37^{\circ} \mathrm{C}$ in a $5 \% \mathrm{CO}_{2}$ atmosphere. Cells were suspended by trypsin-EDTA (Hyclone) and separated $1.5 \times 10^{5} / \mathrm{ml}$ at each plates, every $48 \mathrm{~h}$.

Cell proliferation assay (MTT). Cells were seeded at 4,000/ $\mathrm{ml}$ each well in 96-well plate, and incubated $24 \mathrm{~h}$. After the incubation, treated with test compound and incubate at $37^{\circ} \mathrm{C}$ in a $5 \% \mathrm{CO}_{2}$ atmosphere. After $24 \mathrm{~h}$, cells were incubated with $20 \mu 1 \mathrm{MTT}(5 \mathrm{mg} / \mathrm{ml}$ with PBS) solution for $1 \mathrm{~h}$. Optical densities of solution, in each well, were determined by microplate reader (Bio-Rad Laboratories, Inc., Tokyo, Japan) at $595 \mathrm{~nm}$.

Observation of cellular morphology and actin-cytoskeleton. Cells were seeded $1 \times 10^{5} / \mathrm{ml}$ in 12-well plate with cover glasses. After treatment the indicated time and dose at $37^{\circ} \mathrm{C}$ in a $5 \% \mathrm{CO}_{2}$ atmosphere, the cells were visualized with the use of bright field microscopy (Carl Zeiss, Thornwood, NY, USA) for morphological changes. For the actin-cytoskeleton observation, the cells, which were treated with compound, were fixed with $3.7 \%$ formaldehyde for $20 \mathrm{~min}$ and pemeabilized with $0.2 \%$ Triton X-100 for 20 min. Cells were washed with PBS twice and reacted with E-cadherin antibody overnight at $4^{\circ} \mathrm{C}$. Cells were washed with PBS twice and reacted with the secondary antibody and stained with $0.1 \%$ Phalloidin-FITC for $40 \mathrm{~min}$ and fluorescence was detected by fluorescence microscopy (Carl Zeiss).

Wound healing assay. Cells were seeded $2.5 \times 10^{6} / \mathrm{ml}$ in a 6 -well plate, and incubated to $100 \%$ confluence at well. After the incubation a wound was made in the cell monolayer at center of well, and the cells were treated with TJE at the indicated dose for $24 \mathrm{~h}$. The healing of the wound was detected with a bright field microscope (Carl Zeiss).

Invasion assay. Quantitative cell invasion assays were performed using a modified Boyden chamber (Costar-Corning, NY, USA) with an $8.0-\mu \mathrm{m}$ pore polycarbonate membrane inserts with Matrigel in 24-well plates in a routine manner. The lower chamber was filled with complete medium for control and complete medium with TJE at the indicated dose and EGF. The MCF-7 cells $\left(5 \times 10^{4}\right.$ cells $\left./ \mathrm{ml}\right)$ in serum-free medium were added into the upper chamber. The cells were allowed to invade for $24 \mathrm{~h}$ at $37^{\circ} \mathrm{C}$. The non-invasive cells were removed from the upper surface of the membrane by scraping with a cotton swab, and the invasive cells were stained with crystal violet and photographed under a bright field microscope.

Immunofluorescence staining. Cells were seeded at $1 \times 10^{5} / \mathrm{ml}$ in a 12-well plate with cover glasses. After treatment for the indicated time and dose at $37^{\circ} \mathrm{C}$ in a $5 \% \mathrm{CO}_{2}$ atmosphere, the cells were fixed with $3.7 \%$ formaldehyde for $20 \mathrm{~min}$ and pemeabilized with $0.2 \%$ Triton X-100 for 20 min. Cells were washed with PBS twice and reacted with E-cadherin antibody overnight at $4^{\circ} \mathrm{C}$. Cells were washed with PBS twice and reacted with the secondary antibody and stained with $0.1 \%$ Phalloidin-FITC for $40 \mathrm{~min}$. For counter staining, cells were stained with Hoechst 33342 for 20 min and fluorescence was detected by confocal microscopy (Carl Zeiss).

Transient transfection with small interfering RNA. Small interfering RNA (siRNA) was purchased by Dharmacon (Dharmacon, Chicago, IL, USA). For transient transfection, cells were seeded at $5 \times 10^{3} / \mathrm{ml}$ on a 6 -well plate with antibioticfree medium. After incubation overnight, targeting siRNA was transfected using DharmaFECT1 transfection reagent (Dharmacon) according to the manufacturer's instructions. After incubation for $72 \mathrm{~h}$, cells were treated with TJE and EGF for the indicated time.

Western blotting. Cells were seeded at $1 \times 10^{5} / \mathrm{ml}$ in a 6 -well plate and incubated for $24 \mathrm{~h}$. After the incubation, cells were treated with test compound for $6 \mathrm{~h}$ at $37^{\circ} \mathrm{C}$ in a $5 \% \mathrm{CO}_{2}$ atmosphere. Cells were rinsed twice with ice-cold PBS and scraped with lysis buffer $(50 \mathrm{mM}$ Tris-HCl pH 8.0, $150 \mathrm{mM}$ $\mathrm{NaCl}, 1 \% \mathrm{NP} 40,0.5 \%$ sodium deoxycholate, $1 \mathrm{mM}$ PMSF) and subjected to the western blot analysis. First antibody was applied overnight at $4^{\circ} \mathrm{C}$ and the second antibody for $75 \mathrm{~min}$ at room-temperature with slow agitation.

Polymerase chain reaction (PCR). Total RNA was extracted using RiboEx (GeneAll, GeneAll biotechnology, Seoul, Korea) according to the manufacturer's instructions, and cDNA was generated using ReverseAids cDNA synthesis kit 
Table I. Primer sequences for the amplification of the target gene.

\begin{tabular}{|c|c|c|c|}
\hline Gene & Primer sequence $\left(5^{\prime}-3^{\prime}\right)$ & Amplification size (bp) & Annealing temperature $\left({ }^{\circ} \mathrm{C}\right)$ \\
\hline \multirow[t]{2}{*}{ E-cadherin } & For: CGGACGATGATGTGAACACC & & \\
\hline & Rev: TTGCTGTTGTGCTTAACCCC & 213 & 60.0 \\
\hline \multirow[t]{2}{*}{$\mathrm{N}$-cadherin } & For: GACAATGCCCCTCAAGTGTT & & \\
\hline & Rev: CCATTAAGCCGAGTGATGGT & 179 & 59.5 \\
\hline \multirow[t]{2}{*}{ Vimentin } & For: GAGAACTTTGCCGTTGAAG & & \\
\hline & Rev: TCCAGCAGCTTCCTGTAGGT & 170 & 59.5 \\
\hline \multirow[t]{2}{*}{ Snail } & For: CCCCAATCGGAAGCCTAACT & & \\
\hline & Rev: ACAGAGTCCCAGATGAGCA & 157 & 60.0 \\
\hline \multirow[t]{2}{*}{ Slug } & For: CTTTTTCTTGCCCTCACTGC & & \\
\hline & Rev: GCTTCGGAGTGAAGAAATGC & 224 & 59.0 \\
\hline \multirow[t]{2}{*}{ Twist } & For: GTCCGCAGTCTTACGAGGAG & & \\
\hline & Rev: CCAGCTTGAGGGTCTGAATC & 159 & 57.5 \\
\hline \multirow[t]{2}{*}{ ZEB1 } & For: TGGACTGAGTGTGGAAAAGC & & \\
\hline & Rev: TGGTGATGCTGAAAGAGACG & 237 & 60.0 \\
\hline \multirow[t]{2}{*}{ ZEB2 } & For: TTCCTGGGCTACGACCATAC & & \\
\hline & Rev: GCCTTGAGTGCTCGATAAGG & 393 & 60.0 \\
\hline \multirow[t]{2}{*}{ GAPDH } & For: CAAGGTCATCCATGACAACTTTG & & \\
\hline & Rev: GTCCACCACCCTGTTGCTGTAG & 496 & 58.0 \\
\hline
\end{tabular}

(Thermo Scientific, Waltham, MA, USA) according to the manufacturer's instructions. RT-PCR was performed with the following temperature profile: a pre-denaturation step of $10 \mathrm{~min}$ at $95^{\circ} \mathrm{C}$, followed by 35 cycles of $95^{\circ} \mathrm{C}$ for $30 \mathrm{sec}$, annealing temperature for $30 \mathrm{sec}$ and $72^{\circ} \mathrm{C}$ for $30 \mathrm{sec}$ and a final exposure at $72^{\circ} \mathrm{C}$ for $10 \mathrm{~min}$. The specific primers are listed in Table I.

Statistical analysis. Cell viability and invasive cells, EGFR activities were statistically analyzed using unpaired t-test (SPSS, Chicago, IL, USA). P $<0.05$ was considered statistically significant.

\section{Results}

TJE reduces cell proliferation. The anti-proliferation effects of TJE were investigated through regulation of EGFR activities by treating cells with TJE $(10-100 \mu \mathrm{g} / \mathrm{ml})$ and co-treatment with TJE (10-100 $\mu \mathrm{g} / \mathrm{ml})$ and EGF $(50 \mathrm{ng} / \mathrm{ml})$ for $24 \mathrm{~h}$. Then the cells were measured for cell proliferation. It was shown that there was a decrease in cell proliferation in both the TJE treated groups and TJE/EGF co-treatment groups (Fig. 1).

TJE suppresses cell migration and invasion through regulation of EGF-induced EMT. Morphological changes of MCF-7 breast cancer cells after EGF treatment in the absence or presence of TJE were observed by bright field and fluorescence microscopy. EGF induced morphological changes were reversible $24 \mathrm{~h}$ after treatment. Cells appeared to have lost cell to cell contact. Moreover, cells treated with EGF showed changes

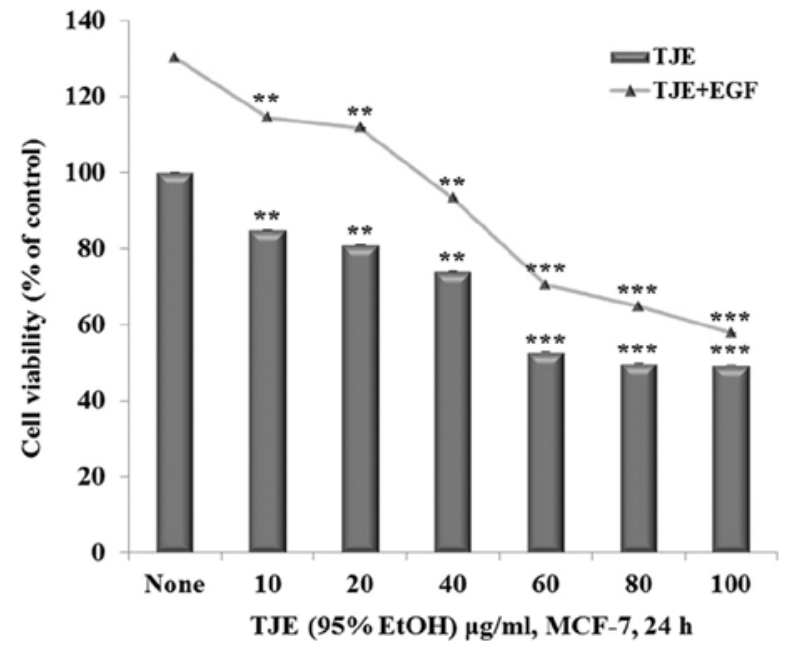

Figure 1. Cell proliferation rate was measured by MTT assay. Cells were treated with the indicated concentrations of TJE or co-treated with EGF $50 \mathrm{ng} / \mathrm{ml}$ after TJE treatment for $24 \mathrm{~h} .{ }^{* *} \mathrm{P}<0.01,{ }^{* * *} \mathrm{P}<0.001$ (each experiment, $\mathrm{n}=3$ ).

in the actin-cytoskeleton architecture and morphology with lamellipodia and filopodia becoming clearly visible. A complete inhibition of these changes was observed in groups with TJE treatment (Fig. 2A).

Also the anti-migration and anti-invasion abilities of TJE were investigated via EGF regulation. Anti-migration ability was investigated using a wound healing assay. While EGF treated cells grew to confluence in a mono-layer, TJE treated 
A

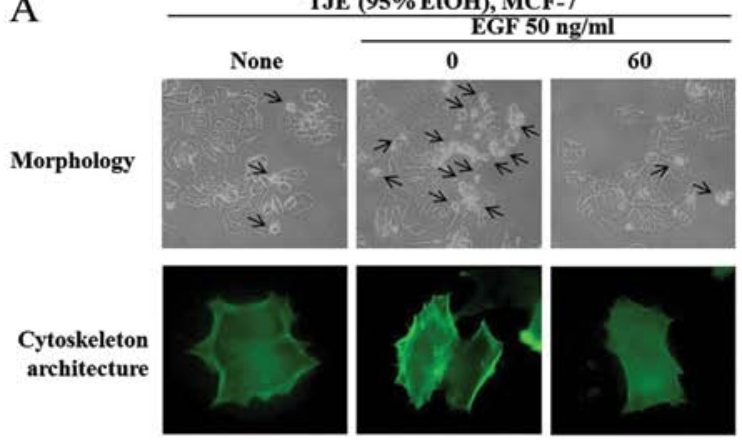

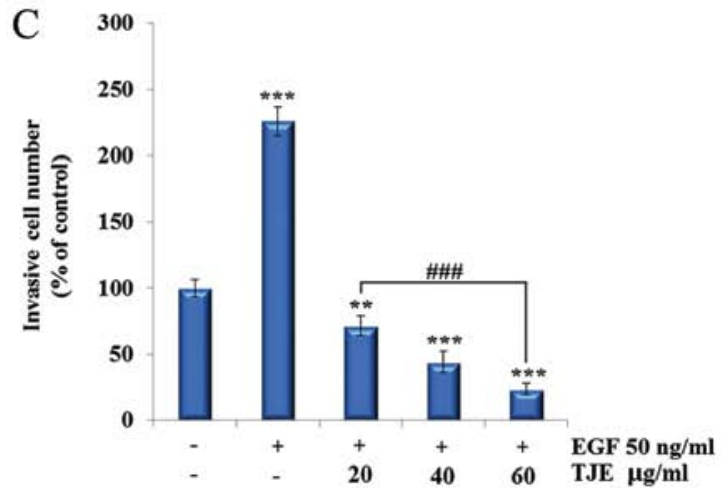

B

TJE (95\% EtOH), MCF-7

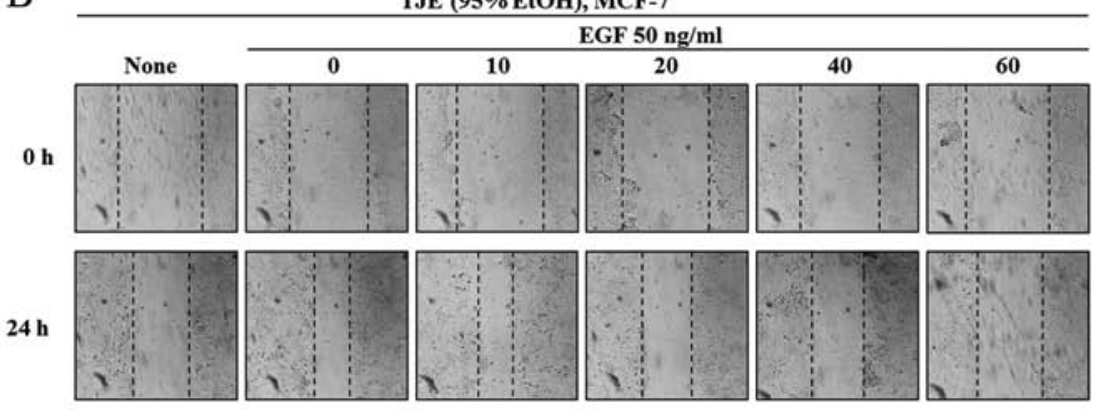

$\mathrm{D}$
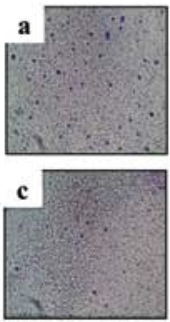
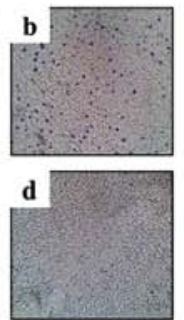

Figure 2. Involvement of TJE in MCF-7 breast cancer cell motility. (A) Morphological changes and cytoskeletal polarization of cells after EGF treatment in the absence or presence of TJE. Morphological changes of cells were observed using a bright-field microscopy. Arrows indicate EMT cells, which appeared to have lost cell to cell contact. In addition, actin-cytoskeletal polarization was observed by fluorescence microscopy. (B) Anti-migration abilities were detected by wound healing assay. Representative images of the reduction of MCF-7 breast cancer cells by TJE treatment with EGF. (C) Invasion of MCF-7 breast cancer cells with or without TJE treatment. Invasive cells were determined by counting cells in four microscopic fields per sample. Compared to control; ${ }^{2} \mathrm{P}<0.05$, ${ }^{* *} \mathrm{P}<0.01,{ }^{* * *} \mathrm{P}<0.001$ and compared to EGF-treated group; ${ }^{\# \# \#} \mathrm{P}<0.001$ (each experiment, $\mathrm{n}=3$ ). NS, not significant. (D) Invasion of MCF-7 breast cancer cells with or without TJE treatment. Invasive cells were stained by crystal violet for counting cells in microscopic fields per sample. a, control; b, EGF $50 \mathrm{ng} / \mathrm{ml}$; c, TJE $40 \mu \mathrm{g} / \mathrm{ml}$ in EGF; d, TJE $60 \mu \mathrm{g} / \mathrm{ml}$ in EGF.

groups did not grow to confluence and the results were dosedependent. EGF induced cell invasive activity, but there was a decrease in invasive cells dose-dependently in the TJE co-treated groups (Fig. 2B-D).

Taken together, these data show that TJE suppresses cell movement for abnormal metastasis through the regulation of EGF-induced EMT.

TJE regulates EGFR activation and its downstream proteins. To examine how TJE reduces cell metastasis, the control by TJE of the activation of EGFR and its downstream pathways such as Akt and Erk was investigated by using western blotting to analyze changes in levels of p-EGFR, p-Akt, and p-Erk after co-treatment with different concentrations of TJE and EGF. The results show that TJE strongly suppresses EGFR activation and its downstream pathways in a dose-dependent manner (Fig. 3A). Using a specific chemical inhibitor, it was demonstrated that EGF-induced EMT is related to Akt and Erk signaling pathways and TJE is able to repress both these pathways (Fig. 3B).

TJE regulates expression of actin polarization related proteins and EMT marker genes. Gene and protein expression were analyzed to determine whether or not EGF treated MCF-7 cells show differences in their expression of actin polarization proteins and EMT marker genes with TJE treatment.

By western blotting, it was determined that actin polarization related proteins such as VEGF and p-VASP were upregulated by EGF stimulation. In addition, EGF treatment increased the expression of E-cadherin transcriptional regulators, ZEB1, ZEB2, and Snail and E-cadherin repressors such as Slug and Twist as well as expression levels of mesenchymal markers $\mathrm{N}$-cadherin and vimentin. On the contrary, these changes were inhibited in a dose-dependent manner in the EGF-stimulation groups treated with TJE (Fig. 3C).

Using a specific chemical inhibitor, it was demonstrated that EGF-stimulated expression of actin polarization-related proteins and EMT markers is through Akt and Erk signaling pathways and that TJE is able to repress EGF-induced expression through reduced Akt and Erk activation. Groups treated with Avastin (VEGF inhibitor) showed a decrease in VASP phosphorylation as well as EMT markers, which indicates that reduction of actin polarization and EMT by TJE was also through control of VEGF expression (Fig. 3D).

Regulation of VEGF, p-VASP, and EMT markers by TJE treatment through control of EGFR activation. It was confirmed that TJE controls actin polarization and EMT through regulation of EGFR activation by comparing groups treated with the specific EGFR inhibitor GW 2974, and with TJE. The results show that, like the EFGR specific inhibitor group, TJE downregulates EGFR phosphorylation. Moreover, expression of actin polarization proteins and EMT markers is reduced in both TJE and inhibitor treated groups (Fig. 4B). Based on the above data, EGFR knock-down using siRNA transfection was performed to confirm that TJE decreases 
$\mathbf{A}$

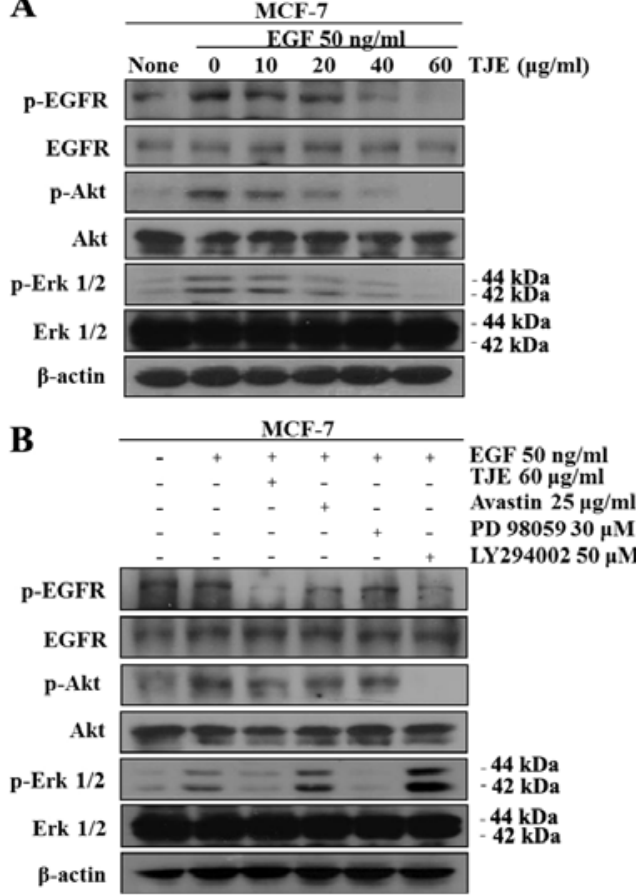

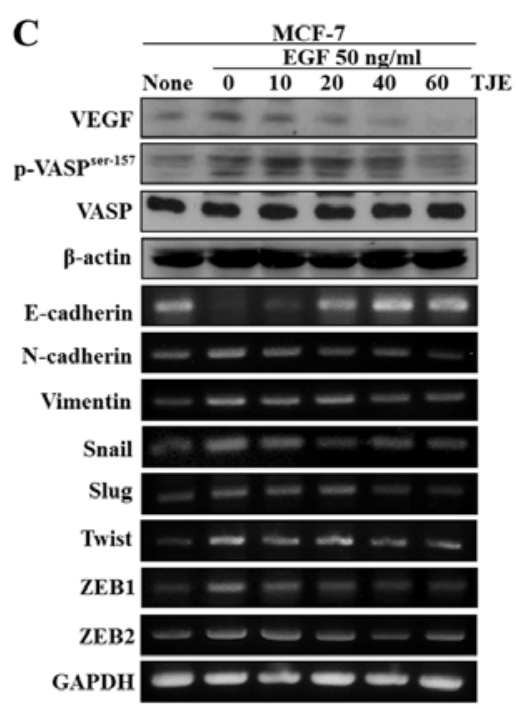
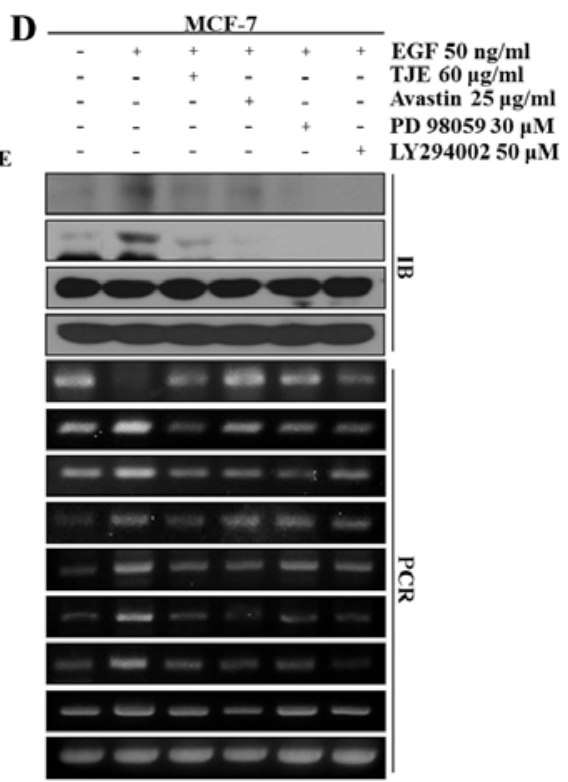

Figure 3. Evaluation of the inhibitory effect of TJE on EGFR pathway and EMT. Specific inhibitors were applied for 30 min before EGF-stimulation. (A) The change of EGFR phosphorylation levels was examined and its downstream protein phosphorylation levels were detected by western blotting. (B) Using a specific chemical inhibitor, activation of EGFR and its downstream protein activation levels were detected by western blotting. (C) The change of actin polarization protein levels was detected by western blotting. In addition, EMT marker gene expression levels were examined by PCR. (D) Using a specific chemical inhibitor, expression levels of actin polarization proteins and EMT marker genes were examined.

A

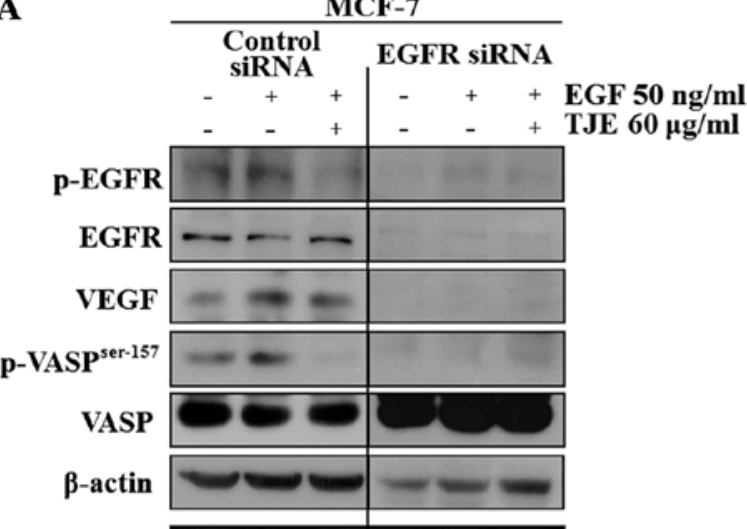

N-cadherin

Vimentin

Snail

Slug

Twist

ZEB1

ZEB2

GAPDH
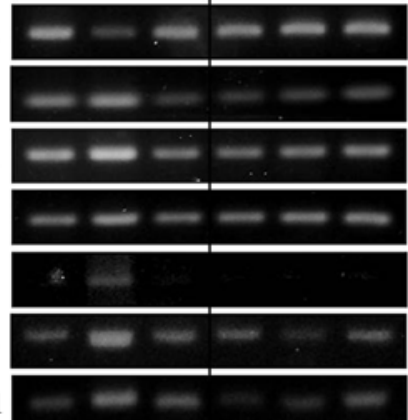

$-=$

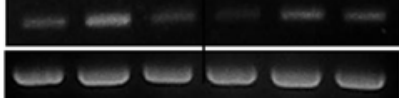

B
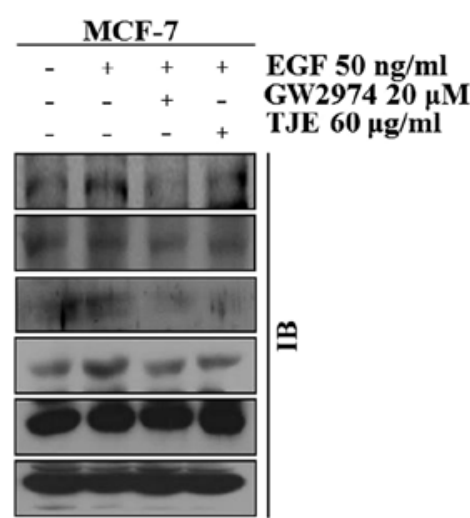

$\cong$

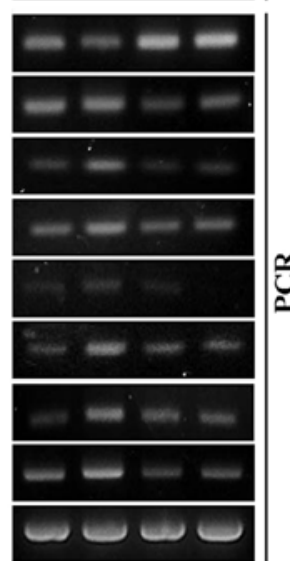

Figure 4. Inhibitory effect of TJE on EGF-induced EMT is presented by regulated EGFR activation. (A) The change of EGFR phosphorylation and actin polarization protein expression levels were detected by western blotting. EMT marker genes were examined by PCR. (B) Cells were transfected with EGFR siRNA using DharmaFECT and treated with TJE in EGF-stimulation. The change of EGFR phosphorylation and actin polarization protein expression levels were detected by western blotting. In addition, EMT marker genes were examined by PCR. 
TJE, MCF-7

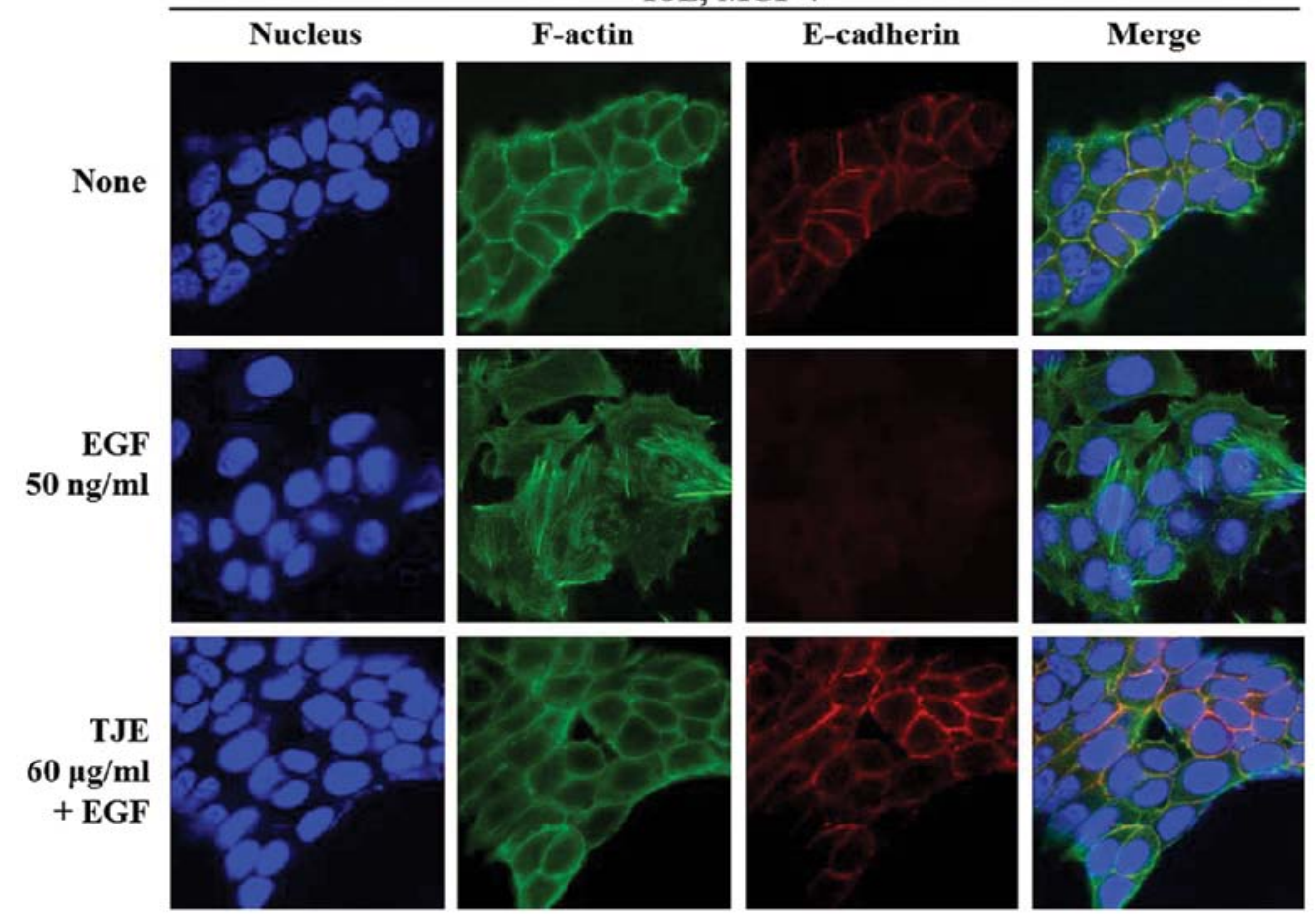

Figure 5. Inhibitory effect of TJE on reduced cell-to-cell junction by EGF-stimulation. Cells were treated with the indicated concentration of TJE in EGF-stimulation and stained the F-actin (green), E-cadherin (red). For the counter staining, a nucleus stained by Hoechst 33342.

EMT via the EGFR pathway. For the EGFR knock-down group, there was no change in expression of VEGF, p-VASP, and EMT markers with EGF-stimulation and the absence of TJE (Fig. 4A).

TJE regulates actin polarization and $E$-cadherin expression by controlling EGFR activation. Previous studies have found a significant correlation between E-cadherin and cell to cell contact. While E-cadherin has been considered as an active suppressor of invasion and migration in many epithelial cancer cells through induced adhesion ability to the extracellular matrix, EGF induces invasion and migration through the expression of an E-cadherin regulator and suppressor $(18,19,30)$.

Immunofluorescence analysis of E-cadherin and F-actin with or without TJE in EGF-stimulation shows that despite EGF-stimulation, TJE upregulated expression of E-cadherin and reduced cytoskeleton polarization (Fig. 5).

\section{Discussion}

Regulation of gene expression by EGF results in modulation of EMT, and especially EMT is a key process in breast cancer progression. Previous studies have found that breast cancer cells and other carcinoma induce EMT when cells are exposed to EGF (30-32); thus, modulating EGF is an obvious strategy to regulate breast cancer progression and abnormal metastasis. In this study, we showed that MCF-7 breast cancer cells can induce EMT by EGF-stimulation and that treatment with TJE leads to the repression of EGFR pathways. TJE induced the epithelial phenotype and completely inhibited EGF-stimulated EMT.
EGF-exposed MCF-7 cells undergo EMT and acquire a mesenchymal phenotype with increased mobility and cytoskeleton polarization. In addition, EGF induces expression of actin polarization-related proteins and EMT marker genes. This effect leads to decreased expression of E-cadherin and is associated with the tumor stage and clinicopathological features. These effects usually activate several pathways through the EGF receptor (30). The two major intracellular signaling pathways activated by EGFR are the Erk MAP kinase pathway and the PI3K/Akt pathway. Previous research has focused on an anti-metastasis effect from one of these pathways, but not from both. As a consequence, while it was possible to discover the reduction in EMT from one of the EGFR downstream signaling pathways, the effect of the other pathway was unclear (33-35); on the other hand, in this study we found that TJE treatment led to a decrease in EGF-induced EMT though blocking of both pathways. TJE had a similar effect to the use of the inhibitors PD 98059 for Erk inhibition and LY 294002 for Akt inhibition (Fig. 3). Moreover, using the EGFR specific inhibitor GW 2974 and EGFR knock-down by siRNA transfection, it was confirmed that TJE regulates EGFR activation and reduces EGF-stimulated EMT through control of EGFR activation and its downstream pathways (Fig. 4).

Breast cancer is the leading cause of cancer death among females worldwide and accounted for $14 \%$ of total cancer deaths in 2008 (24). Almost all deaths were caused by abnormal metastasis such as invasion to other organs or lymph nodes (36-38). Moreover, recently breast cancer has been diagnosed frequently in eastern countries and this is believed to reflect a change of dietary patterns (25). For this reason, researchers have been trying to find food ingredients that have a beneficial effect for anti-metastasis in breast cancer. 
This study describes for the first time the ability of an extract from fruit of Torilis japonica to inhibit EGF-stimulated EMT in MCF-7 breast cancer cells. TJE downregulates EGFR activation and both its downstream pathways, the Erk MAP kinase and Akt signaling pathways. Also TJE treatment results in suppression of EGF-induced EMT by inducing the cell adherent related gene E-cadherin and decreasing mesenchymal markers with the E-cadherin suppressor gene. Taken together, these results suggest that TJE has the potential to interfere with EGFR signaling and act as a suppressor of abnormal metastasis in MCF-7 breast cancer.

\section{Acknowledgements}

This study was supported by the Korea Research Foundation Grant (KRF-2010-0021402).

\section{References}

1. Hay ED: An overview of epithelia-mesenchymal transformation. Acta Anat 154: 8-20, 1995

2. Kalluri R and Neilson EG: Epithelial-mesenchymal transition and its implications for fibrosis. J Clin Invest 112: 1776-1784, 2003.

3. Kalluri R and Weinberg RA: The basic of epithelial-mesenchymal transition. J Clin Invest 119: 1420-1428, 2009.

4. Thiery JP, Acloque H, Huang RY and Nieto MA: Epithelialmesenchymal transition in development and disease. Cell 139: 871-890, 2009

5. Acloque H, Adams MA, Fishwick K, Bronner-Fraser M and Nieto MA: Epithelial-mesenchymal transitions: the importance of changing cell state in development and disease. J Clin Invest 199: 1438-1449, 2009.

6. Foroni C, Broggini M, Generali D and Damia G: Epithelialmesenchymal transition and breast cancer: role, molecular emchanisms and clinical impact. Cancer Treat Rev 38: 689-697, 2012.

7. Moreno-Bueno G, Portillo F and Cano A: Transcriptional regulation of cell polarity in EMT and cancer. Oncogene 27: 6958-6969, 2008.

8. Klymkikowsky MW and Savagner P: Epithelial-mesenchymal transition: a cancer researcher's conceptual friend and foe. Am J Pathol 174: 1588-1593, 2009.

9. Ahmed N, Maines-Bandiera S, Quinn MA, Unger WG, Dedhar S and Auersperg N: Molecular patheways regulating EGF-induced epithelia-mesenchymal transition in human ovarian surface epithelium. Am J Physiol Cell Physiol 290: C1532-C1542, 2006.

10. Bhowmick NA, Chytil A, Plieth D, Gorska AE, Dumont N, Shappell S, Washingtom MK, et al: TGF- $\beta$ signaling in fibroblasts modulation the oncogenic potential of adjacent epithelia Science 6: 848-851, 2004

11. Suo Z, Risberg B, Karlsson MG, Villman K, Skovlund E and Nesland JM: The expression of EGFR family ligands in breast carcinoma. Int J Surg Pathol 10: 91-99, 2002.

12. Ramapul RS, Pinder SE, Wencyk PM, Nicholson RI, Blamey RW, Robertson JF and Ellis IO: Epidermal growth factor receptor status operable invasive cancer: is it of any prognostic value? Clin Cancer Res 10: 2578, 2004.

13. Sasaki T, Hiroki K and Yamashita Y: The role of epidermal growth factor receptor in cancer metastasis and microenviromental. Biomed Res Int 2013: 546318, 2013.

14. Nieto MA: The snail superfamily of zinc-finger transcription factors. Nat Rev Mol Cell Biol 3: 155-166, 2002.

15. Hajra KM, Chen SY and Fearon ER: The SLUG zinc-finger protein represses E-cadherin in breast cancer. Cancer Res 62 : 1613-1618, 2002

16. Rosivatz E, Becker I, Specht K, Fricke E, Luber B, Busch R, Höfler H, et al: Differential expression of the epithelial-mesenchymal transition regulators Snail, SIP1, and twist in gastric cancer. Am J Pathol 161: 1881-1891, 2002.

17. Vandewalle C, Van Roy F and Berx G: The role of the ZEB family of transcription factors in development and disease. Cell Mol Life Sci 66: 773-787, 2009.
18. Nakajima S, Doi R, Toyoda E, Tsuji S, Wada M, Koizumi M, Tulachan SS, et al: N-cadherin expression and epithelial-mesenchymal transition in pancreatic carcinoma. Clin Cancer Res 10: 4125-4133, 2004

19. Nijkamp MM, Span PN, Hoogsteen LJ, Van der Kogel AJ, Kaanders $\mathrm{JH}$ and Bussink $\mathrm{J}$ : Expression of E-cadherin and vimentin correlates with metastasis formation in head and neck squamous cell carcinoma patients. Radiother Oncol 99: 344-348, 2011.

20. Benz PM, Blume C, Seifert S, Wilhelm S, Waschke J, Schuh K, Gertler F, et al: Differential VASP phosphorylation controls remodeling of the actin cytoskeleton. J Cell Sci 122: 3954-3965, 2009.

21. Krause M, Dent EW, Bear JE, Loureiro JJ and Gertler FB: Ena/VASP proteins: regulators of the actin cytoskeleton and cell migration. Annu Rev Cell Dev Biol 19: 541-564, 2003.

22. Harbeck B, Hüttelmaier S, Schluter K, Jockusch BM and Illenberger S: Phosphorylation of the vasodilator-stimulated phosphoprotein regulates its interaction with actin. J Biol Chem 275: 30817-30825, 2000.

23. He M, Cheng Y, Li W, Liu Q, Liu J, Huang J and Fu X: Vascular endothelial growth factor $\mathrm{C}$ promotes cervical cancer metastasis via up-regulation and activation of RhoA/ROCK-2/moesin cascade. BMC Cancer 10: 170, 2010.

24. Jemal A, Bray F, Center MM, Ferlay J, Ward E and Forman D: Global cancer statistics. CA Cancer J Clin 61: 69-90, 2011.

25. Colditz GA, Sellers TA and Trapido E: Epidemiology - identifying cause and preventability of cancer? Nat Rev Cancer 6: 75-83, 2006.

26. Lee SH, Kim GT, Kim JI, Lim EG, Kim IS and Kim YM: The extract from Lysimachia foenum-graecum induce apoptosis in MCF-7 breast cancer cells. KSSB J 28: 303-309, 2013.

27. Pan SY, Zhou SF, Gao SH, Yu ZL, Zhang SF, Tang MK, Sun JN, et al: New perspectives on how to discover drugs from herbal medicines: CAM's outstanding contribution to modern therapeutics. Evid Based Complement Alternat Med 2013: 6273758, 2013.

28. Li Shizhen: Ben Cao Gang Mu (Compendium of Materia Medica). China, 1593.

29. Zhang Zhongjing: Shang han Lun (Treatise on cold damage disorders). China, 220.

30. Jones JL, Royall JE and Walker RA: E-cadherin relates to EGFR expression and lymph node metastasis in primary breast carcinoma. Br J Cancer 74: 1237-1241, 1996.

31. Holz C, Niehr F, Boyko M, Hristozova T, Distel L, Budach V and Tinhofer I: Epithelial-mesenchymal-transition induced by EGFR activation interferes with cell migration and response to irradiation and cetuximab in head and neck cancer cells. Radiother Oncol 101: 158-164, 2011.

32. Cheng JC, Auersperg N and Leung PC: EGF-induced EMT and invasiveness in serous borderline ovarian tumor cells: a possible step in the transition to low-grade serous carcinoma cells? PLoS One 7: e34071, 2012

33. Vergara D, Valente CM, Tinelli A, Siciliano C, Lorusso V, Acierno R, Giovinazzo G, et al: Resveratrol inhibits the epidermal growth factor-induced epithelial mesenchymal trasition in MCF-7 cells. Cancer Lett 310: 1-8, 2011.

34. Jin Y, Iwata KK, Belldegrum A, Figlin R, Pantuck A, Zhang ZF, Lieberman R. et al: Effect of an epidermal growth factor receptor tyrosine kinase inhibitor in actin remodeling in an in vitro bladder cancer carcinogenesis model. Mol Cancer Ther 5: 1754-1765, 2006.

35. Wallerand H, Cai Y, Wainberg ZA, Garraway I, Lascombe I, Nicolle G, Thiery JP, et al: Phospho-Akt pathway activation and inhibition depends on $\mathrm{N}$-cadherin or phosphor-EGFR expression in invasive human bladder cancer cell lines. Urol Oncol 28 180-188, 2010.

36. Weigelt B, Peterse JL and van't Veer LJ: Breast cancer metastasis: markers and models. Nat Rev Cancer 5: 591-602, 2005.

37. Pinder SE, Ellis IO, Galea M, O'Rouke S, Blamey RW and Elston CW: Pathological prognostic factors in breast cancer. III. Vascular invasion: relationship with recurrence and survival in a large study with long-term follow-up. Histopatology 24: 41-47, 1994.

38. de Boer M, van Dijck JA, Bult P, Borm GF and Tjan-Heijnen VC: Breast cancer prognosis and occult lymph node metastases, isolated tumor cells, and micrometastases. J Natl Cancer Inst 102: 410-425, 2010. 